CLINICAL STUDY

\title{
Fasting insulin has a stronger association with an adverse cardiometabolic risk profile than insulin resistance: the RISC study
}

Susanne R de Rooij, Jacqueline M Dekker, Michaela Kozakova ${ }^{1}$, Asimina Mitrakou ${ }^{2}$, Olle Melander ${ }^{3}$, Rafael Gabriel $^{4}$, Caterina Guidone ${ }^{5}$, Kurt Højlund ${ }^{6}$, Matthew $S$ Murphy ${ }^{7}$, Giel Nijpels and the RISC Group Investigators

Department of Clinical Epidemiology and Biostatistics, Institute for Research in Extramural Medicine, VU University Medical Center, 1081 BT, Amsterdam, The Netherlands, ${ }^{1}$ Department of Internal Medicine, University of Pisa, Pisa, Italy, ${ }^{2}$ Endocrine Unit, Aretaieion Hospital, University of Athens, Athens, Greece, ${ }^{3}$ Hypertension and Cardiovascular Disease, Malmö University Hospital, Lund University, Lund, Sweden, ${ }^{4}$ Unidad de Investigacion, Hospital Universitario La Paz, Madrid, Spain, ${ }^{5}$ Department of Internal Medicine, Catholic University, Rome, Italy, ${ }^{6}$ Department of Endocrinology M, Odense University Hospital, Odense, Denmark and ${ }^{7}$ Department of Endocrinology, Trinity College Dublin, St James' Hospital, Dublin, Ireland

(Correspondence should be addressed to S R de Rooij; Email: s.r.derooij@amc.uva.nl)

\begin{abstract}
Objective: Fasting insulin concentrations are often used as a surrogate measure of insulin resistance. We investigated the relative contributions of fasting insulin and insulin resistance to cardiometabolic risk and preclinical atherosclerosis.

Design and methods: The Relationship between Insulin Sensitivity and Cardiovascular disease (RISC) cohort consists of 1326 European non-diabetic, overall healthy men and women aged 30-60 years. We performed standard oral glucose tolerance tests and hyperinsulinemic euglycemic clamps. As a general measure of cardiovascular risk, we assessed the prevalence of the metabolic syndrome in 1177 participants. Carotid artery intima media thickness (IMT) was measured by ultrasound to assess preclinical atherosclerosis.

Results: Fasting insulin was correlated with all elements of the metabolic syndrome. Insulin sensitivity $(M / I)$ was correlated with most elements. The odds ratio for the metabolic syndrome of those in the highest quartile of fasting insulin compared with those in the lower quartiles was 5.4 (95\% confidence interval (CI) 2.8-10.3, adjusted for insulin sensitivity) in men and 5.1 (2.6-9.9) in women. The odds ratio for metabolic syndrome of those with insulin sensitivity in the lowest quartile of the cohort compared with those in the higher quartiles was 2.4 (95\% CI 1.3-4.7, adjusted for fasting insulin) in men and $1.6(0.8-3.1)$ in women. Carotid IMT was only statistically significantly associated with fasting insulin in both men and women.

Conclusions: Fasting insulin, a simple and practical measure, may be a stronger and independent contributor to cardiometabolic risk and atherosclerosis in a healthy population than hyperinsulinemic euglycemic clamp-derived insulin sensitivity.
\end{abstract}

European Journal of Endocrinology $161223-230$

\section{Introduction}

The gold standard technique to assess insulin sensitivity, the hyperinsulinemic euglycemic clamp, is time consuming, expensive, and stressful for the participant. Therefore, fasting insulin concentrations and measures derived from fasting insulin are often used as a surrogate method to measure insulin resistance (1-4). However, results of a number of studies have suggested that fasting hyperinsulinemia may cause cardiometabolic disease in itself, apart from insulin resistance. Results from a prospective study of 319 Pima Indians followed for 6 years showed that a high fasting insulin concentration was a significant predictor for the development of diabetes, independently of insulin sensitivity as measured by a hyperinsulinemic euglycemic clamp (5). A study that used an intravenous glucose tolerance test (IVGTT) to measure insulin sensitivity found that both insulin sensitivity and fasting and 2-h insulin concentrations were independently associated with the metabolic syndrome (6). Insulin sensitivity (by IVGTT) and fasting insulin were also found to be independently associated with atherosclerosis, as measured by the intima media thickness (IMT) of the carotid artery, in the IRAS study (7). A recent publication of the Relationship between Insulin Sensitivity and Cardiovascular disease (RISC) study group has shown that insulin sensitivity as measured by the hyperinsulinemic euglycemic clamp, obesity, central fat accumulation, and insulin response to an oral glucose 
tolerance test (OGTT) were all independent contributors to the clustering of cardiometabolic risk factors (8).

The relative contribution of fasting hyperinsulinemia and insulin sensitivity as measured by the hyperinsulinemic euglycemic clamp has never been assessed in a western population. In the RISC cohort, both fasting insulin and insulin sensitivity as measured from a hyperinsulinemic euglycemic clamp method were assessed in a very large healthy European population (9). In the present paper, we aimed to entangle the effects of fasting hyperinsulinemia and clamp-derived insulin sensitivity on cardiometabolic risk. We quantified cardiometabolic risk by assessment of the presence of the metabolic syndrome and by assessment of carotid IMT, a marker of preclinical atherosclerosis.

\section{Subjects and methods}

\section{Selection procedures}

The RISC cohort consists of clinically healthy men and women aged between 30 and 60 years. Cohort members were recruited by 19 research centers in 14 European countries. Detailed information on inclusion can be found elsewhere (9). The local Medical Ethics committee of each participating research center approved the study. All participants received oral and written explanations of the measurements and gave written informed consent. A total of 1538 persons participated, of whom 32 dropped out during the study and 180 were excluded following the basal clinical measurements. Of the remaining 1326 participants, 1177 had complete data on fasting insulin, $M / I$, and all characteristics of the metabolic syndrome. Forty-four percent were men and the mean age was $43.8( \pm 8.3)$ years.

\section{Measurements: basal}

We measured height on a clinic stadiometer, weight and fat-free mass with the TANITA bioimpedance balance (Tanita International Division, UK), and waist circumference with a tape measure. Blood pressure was taken as the median of three measures performed in a sitting position by an automatic blood pressure measuring device (OMRON 705 cp, OMRON Healthcare Europe, Hoofddorp, The Netherlands). Fasting blood samples were taken to assess lipids. We performed a six-point $75 \mathrm{~g}$ OGTT including measurements of fasting and 2-h glucose and insulin concentrations. Glucose was measured by the Glucose Oxidase Technique (Cobas Integra, Roche). Insulin was measured by a specific time-resolved fluoroimmunoassay (AutoDELFIA Insulin kit, Wallac Oy, Turku, Finland). Assay characteristics were as follows: intra-assay variation $1.7 \%$ and interassay variation $3.5 \%$. A lifestyle and medical history questionnaire was used to collect information on socioeconomic status, personal medical history, and family history of diabetes in first-degree relatives, as well as information on smoking and alcohol drinking habits, physical activity, and use of medication.

\section{Measurements: insulin sensitivity}

Insulin sensitivity was estimated using the hyperinsulinemic euglycemic clamp, which was performed after the exclusion criteria and local assay results had been determined. The target plasma glucose concentration during the clamp was between 4.5 and $5.5 \mathrm{mmol} / \mathrm{l}$. Insulin was infused at a rate of $240 \mathrm{pmol} / \mathrm{min}$ per $\mathrm{m}^{2}$. To ensure plasma glucose remained within $0.8 \mathrm{mmol} / \mathrm{l}$ $( \pm 15 \%)$ of the target glucose concentration, it was measured at 5 - to 10 -min intervals. The $M$ value was averaged over the final $40 \mathrm{~min}$ of the 2-h clamp and normalized by the fat-free mass. Insulin sensitivity was expressed as the ratio of the $M$ value to the mean plasma insulin concentrations measured during the final 40 min of the clamp $(M / I)(10)$.

\section{Measurements: carotid IMT}

We followed a validated scanning and reading protocol for ultrasound measurement of carotid artery IMT (11, 12). Longitudinal B-mode images of the distal left and right common carotid artery, carotid bulb, and the origin of internal carotid artery were obtained in each center by trained and certified technicians using highresolution ultrasound scanners (all with 7-5 to 10.0 MHz linear-array transducer). The whole imaging procedure was recorded on S-VHS tape. Images were evaluated in a centralized reading center by a single reader (M K) blinded to clinical data and using a highresolution video recorder (Panasonic AG-MD830) coupled with the computer-driven image analysis system. For the purpose of this study, digitized enddiastolic frames of the left and right common carotid arteries were selected. Near- and far-wall IMT was measured manually $\sim 1 \mathrm{~cm}$ before the flow divider in five measurement points, and the mean value was calculated for each wall. The IMT value used in the analyses was computed as an average of all carotid walls available (up to four walls). Intra-observer variability of IMT measures was tested in 100 randomly chosen scans calculating the average percent difference between the first and second readings relative to the first reading. The mean difference was $4.6 \pm 3.0 \%$.

\section{Definition of the metabolic syndrome}

We used the National Cholesterol Education Panel (NCEP) definition, with the 2005 revised threshold for fasting glucose, to diagnose the metabolic syndrome $(13,14)$. According to this definition, metabolic syndrome is present when three or more of the following characteristics apply: fasting glucose concentration $\geq 5.6 \mathrm{mmol} / \mathrm{l}$, waist 
circumference $>102 \mathrm{~cm}$ in men and $>88 \mathrm{~cm}$ in women, blood pressure $\geq 130 / 85 \mathrm{mmHg}$, triglyceride concentration $\geq 1.7 \mathrm{mmol} / \mathrm{l}$, high density lipoprotein (HDL) cholesterol $<1.03 \mathrm{mmol} / \mathrm{l}$ in men and $<1.29 \mathrm{mmol} / \mathrm{l}$ in women. This definition does not rely on the presence of insulin resistance, as some other definitions of the metabolic syndrome do.

\section{Statistical methods}

We calculated fat mass as the difference between body weight and fat-free mass. The average insulin response during the OGTT was calculated by the trapezoid rule $((15 \times$ ins $0 \mathrm{~min}+30 \times$ ins $30 \mathrm{~min}+45 \times$ ins $60 \mathrm{~min}$ $+30 \times$ ins $120 \mathrm{~min}) / 120)$. Variables with skewed distributions are represented by medians and interquartile ranges, and were log-transformed when used in a linear regression analysis. We split the cohort according to quartiles of fasting insulin concentrations and $M / I$ values. We calculated sex-specific quartiles because mean fasting insulin concentrations were lower in women than men $(9.8 \%, P<0.01)$ and $M / I$ values were higher in women than men $(23.1 \%, P<0.01)$. Also, there was evidence for an interaction between sex and fasting insulin on carotid IMT $(P<0.01)$. We used linear and logistic regression analysis to analyze possible differences between the sex-specific fasting insulin and $M / I$ quartiles on general, lifestyle, and clinical characteristics. Spearman's $\rho$ was applied to quantify the relationships between several cardiometabolic risk factors, fasting insulin concentrations, and $M / I$. We used logistic regression analysis to calculate odds ratios for the relationship of sex, age, and lifestyle variables, fasting insulin, and $M / I$ with the prevalence of the metabolic syndrome and its components. To be able to compare the effects of fasting insulin and $M / I$ on the prevalence of the metabolic syndrome and its components, we calculated odds ratios between the lower and higher quartiles and made $2 \times 2$ tables. Odds ratios were adjusted for $M / I$ when investigating fasting insulin and for fasting insulin when investigating $M / I$. To analyze the associations between carotid IMT and fasting insulin and $M / I$, we log-transformed IMT values and used it as the dependent variable in a linear regression analysis. To test for a possible interaction between fasting insulin and $M / I$ on the prevalence of the metabolic syndrome and carotid IMT, we added the interaction term ins $0 \times M / I$ to the regression analyses. Possible multi-collinearity between fasting insulin and $M / I$ was studied by the examination of the tolerance statistic; when the tolerance statistic was $<0.1$, the regression model was considered to be disturbed by multi-collinearity. In all models, we adjusted for (sex), age, and study center. The IMT models were additionally adjusted for the classical risk factors smoking, systolic blood pressure (SBP), and HDL cholesterol. We considered differences to be statistically significant if $P$ values were $<0.05$.

\section{Results}

\section{Associations between cardiometabolic risk factors, fasting insulin, and M/I}

Table 1 shows means or medians of cardiometabolic risk factors for participants in the highest sex-specific quartile of fasting insulin concentrations versus participants in the three lower quartiles. Table 2 shows the same for participants in the lowest sex-specific quartile of $M / I$ versus the three higher quartiles. Table 3 shows Spearman's $\rho$ correlations between fasting insulin, $M / I$, and the cardiometabolic risk factors incorporated in the metabolic syndrome. Fasting insulin concentrations in men as well as women were significantly correlated with all elements of the metabolic syndrome. $M / I$ was significantly correlated with most elements, but not with fasting glucose concentrations in either men or women or with SBP in men. The correlation between fasting insulin concentrations and $M / I$ in men was $-0.54(P<0.01)$ and in women it was -0.44 $(P<0.01)$. The correlation between fasting insulin and average OGTT insulin response was 0.67 $(P<0.01)$ in men and $0.61(P<0.01)$ in women; the correlation between $M / I$ and average insulin response in men was $-0.653(P<0.01)$ and in women was $-0.52(P<0.01)$.

\section{The metabolic syndrome}

The prevalence of the metabolic syndrome in the RISC cohort was $10.0 \%$. Men more often had the metabolic syndrome than women (12.1 vs $8.4 \%, P$ for difference $=0.02)$. Age was significantly associated with the metabolic syndrome, with an odds ratio of $1.4(95 \%$ confidence interval (CI) 1.1-1.8) per 10 years of age. Smoking was also significantly associated with the metabolic syndrome. Per $10 \mathrm{~g}$ tobacco intake per day (about eight cigarettes), the odds ratio for having the metabolic syndrome was $1.2(1.0-1.4)$. Although there seemed to be some differences in the prevalence of the metabolic syndrome between study centers (range: 0.0$19.3 \%)$, study center was not a statistically significant confounder $(P=0.38)$.

\section{Associations between metabolic syndrome, fasting insulin, and $\mathrm{M} / \mathrm{I}$}

Table 4 shows the prevalence of the metabolic syndrome according to high or low quartiles of fasting insulin and $M / I$. In both men and women, the prevalence of metabolic syndrome was the lowest when being in the lower fasting insulin quartile and higher M/I quartiles; higher when being in the lower fasting insulin quartile and the lowest $M / I$ quartile; even higher when in the highest fasting insulin quartile and higher $M / I$ quartiles; and the highest when in the highest fasting insulin quartile and the lowest $M / I$ quartile. 
Table 1 General, lifestyle, and clinical characteristics according to sex and quartiles of fasting insulin concentrations.

\begin{tabular}{|c|c|c|c|c|c|}
\hline & \multicolumn{2}{|c|}{ Men } & \multicolumn{2}{|c|}{ Women } & \multirow[b]{2}{*}{ All } \\
\hline & QI-III & QIV & QI-III & QIV & \\
\hline \multicolumn{6}{|l|}{ General characteristics } \\
\hline$n$ & 394 & 128 & 495 & 160 & 1177 \\
\hline Age (years) & $43.1(8.6)$ & $43.4(8.0)$ & $44.1(8.2)$ & $45.4(8.1)$ & $43.8(8.3)$ \\
\hline Family history of diabetes (\%) & 23 & 32 & 26 & 41 & 27 \\
\hline \multicolumn{6}{|l|}{ Lifestyle characteristics } \\
\hline Frequency of smoking (\%) & 26 & 32 & 24 & 26 & 26 \\
\hline Alcohol intake (grams/week) ${ }^{a}$ & $74(122)$ & $81(136)$ & $39(62)$ & $26(43)^{*}$ & $50(90)$ \\
\hline \multicolumn{6}{|l|}{ Clinical characteristics } \\
\hline BMI $\left(\mathrm{kg} / \mathrm{m}^{2}\right)^{\mathrm{a}}$ & $25.5(3.6)$ & $28.5(3.9)^{*}$ & $23.4(4.1)$ & $27.5(6.9)^{*}$ & $24.9(5.0)$ \\
\hline Waist circumference $(\mathrm{cm})$ & $90.8(8.9)$ & $100.4^{*}(10.2)$ & $78.2(9.8)$ & $88.9^{*}(12.8)$ & $86.3(12.5)$ \\
\hline Fat mass $(\mathrm{kg})$ & $16.9(6.6)$ & $24.4(8.5)^{\star}$ & $20.2(6.5)$ & $29.2(6.1)^{*}$ & $20.8(8.7)$ \\
\hline Total cholesterol $(\mathrm{mmol} / \mathrm{l})$ & $4.8(0.8)$ & $5.1(1.0)^{\star}$ & $4.7(0.8)$ & $4.9(1.0)$ & $4.8(0.9)$ \\
\hline HDL cholesterol (mmol/l') & 1.3 & $1.1(0.2)^{*}$ & $1.7(0.4)$ & $1.4(0.3)^{*}$ & $1.4(0.4)$ \\
\hline Triglycerides $(\mathrm{mmol} / \mathrm{l})^{\mathrm{a}}$ & $1.0(0.6)$ & $1.5(0.9)^{*}$ & $0.8(0.4)$ & $1.0(0.7)^{*}$ & $0.9(0.6)$ \\
\hline Systolic blood pressure $(\mathrm{mmHg})$ & $122(11)$ & $123(11)$ & $113(12)$ & $117(12)^{*}$ & $117(12)$ \\
\hline Diastolic blood pressure (mmHg) & $76(8)$ & $79(6)^{*}$ & $72(8)$ & $75(7)^{*}$ & $74(8)$ \\
\hline Fasting glucose OGTT' $(\mathrm{mmol} / \mathrm{l})^{\mathrm{a}}$ & $5.2(0.6)$ & $5.4(0.6)^{*}$ & $4.9(0.6)$ & $5.3(0.7)^{\star}$ & $5.1(0.7)$ \\
\hline $2 \mathrm{~h}$ glucose $\mathrm{OGTT}^{\mathrm{b}}(\mathrm{mmol} / \mathrm{l})^{\mathrm{a}}$ & $5.4(1.8)$ & $6.0(2.1)^{*}$ & $5.4(1.8)$ & $6.3(2.4)^{*}$ & $5.6(1.9)$ \\
\hline Fasting insulin $\mathrm{OGTT}^{\mathrm{b}}(\mathrm{pmol} / \mathrm{l})^{\mathrm{a}}$ & $27(16)$ & $59(20)^{\star}$ & $24(14)$ & $56(21)^{\star}$ & $31(23)$ \\
\hline $2 \mathrm{~h}$ insulin $(\mathrm{pmol} / \mathrm{l})^{\mathrm{a}}$ & $114(118)$ & $256(330)^{*}$ & $137(115)$ & $262(248)^{\star}$ & $147(152)$ \\
\hline Average OGTT ${ }^{\mathrm{b}}$ insulin response $(\mathrm{pmol} / \mathrm{l})^{\mathrm{a}}$ & $187(114)$ & $370(285)^{\star}$ & $179(106)$ & $325(172)^{*}$ & $203(154)$ \\
\hline$M / I\left(\mu \mathrm{mol} / \mathrm{min} \text { per } \mathrm{kg}_{\mathrm{ffm}} \text { per } \mathrm{nM}\right)^{\mathrm{a}}$ & $124(76)$ & $73(45)^{*}$ & $160(81)$ & $101(63)^{\star}$ & $130(89)$ \\
\hline IMT in $\mathrm{CCA}^{\mathrm{c}}(\mathrm{mm})^{\mathrm{a}}$ & $0.60(0.11)$ & $0.63(0.11)^{*}$ & $0.58(0.11)$ & $0.60(0.12)$ & $0.59(0.11)$ \\
\hline
\end{tabular}

Data are means (S.D.). * Statistically significant difference $(P<0.05$, adjusted for age and study center) compared with the $75 \%$ lowest fasting insulin values. ${ }^{a}$ Medians (interquartile range) and frequencies; QI-III denotes the $75 \%$ lowest fasting insulin values; QIV denotes the $25 \%$ highest fasting insulin values. boral glucose tolerance test.

Intima media thickness in common carotid artery.

The table seems to show that effects are additive and possibly synergistic.

The regression models showed that fasting insulin and insulin sensitivity, as measured by $M / I$, were both strongly and independently associated with the metabolic syndrome in men as well as women. When combining both variables in one logistic regression model, the odds ratio for having the syndrome was 1.9 (95\% CI 1.4-2.5) per 1 s.D. increase in fasting insulin in men and $2.3(1.8-3.1)$ in women; $1.8(1.1-3.0)$ per 1 s.D. decrease in $M / I$ in men and 1.7 (1.1-2.6) in women. There was some evidence for a synergistic effect: the interaction term fasting insulin $\times M / I$ just reached statistical significance in men but not in women. Per 1 S.D. increase in the interaction term, the odds ratio for having the metabolic syndrome was 2.2 (1.0-4.8).

When combining $M / I$ and average OGTT insulin response in one model, the odds ratio for the metabolic syndrome was $1.4(1.1-1.9)$ per 1 s.D. increase in insulin response in men and $1.6(1.2-2.1)$ in women; 2.4 (1.6-3.3) per 1 S.D. decrease in $M / I$ in men and 2.1 (1.3-3.4) in women. There was no evidence for multicollinearity in these regression models.

Table 5 shows odds ratios for having a characteristic of the metabolic syndrome or having the metabolic syndrome itself according to low or high quartile of fasting insulin (adjusted for $M / I$ ) and $M / I$ (adjusted for fasting insulin). Among male participants in the highest $25 \%$ fasting insulin concentrations of the cohort, the odds ratio for the metabolic syndrome was
5.4 (95\% CI 2.8-10.3; adjusted for $M / I$ ) in comparison with the $75 \%$ of participants with lower fasting insulin concentrations; among female participants, the odds ratio was 5.1 (2.6-9.9). The odds ratio for the metabolic syndrome of men in the lowest quartile of M/I compared with men in the higher quartiles was 2.4 (95\% CI 1.3-4.7; adjusted for fasting insulin); in women it was $1.6(0.8-3.1)$.

\section{Associations between carotid IMT, fasting insulin, and $\mathrm{M} / \mathrm{I}$}

Fasting insulin was associated with carotid IMT in men $(B=0.021(95 \%$ CI $0.010-0.033)$ per S.D. increase, adjusted for age and study center) and in women $(0.012$ (0.002-0.022)). The association between $M / I$ and carotid IMT only showed a trend towards statistical significance in men $(0.011(-0.001$ to 0.022$)$ per s.D. decrease) and women (0.008 (-0.001 to 0.018)). When combining both variables in one linear regression model, $M / I$ became a largely non-significant contributor to the model $(B=0.002(-0.011$ to 0.014$)$ in men and 0.004 ( -0.006 to 0.015$)$ in women); fasting insulin remained a significant contributor $(B=0.020(0.007-$ $0.034)$ in men and 0.011 (0.000-0.034) in women).

Carotid IMT was significantly correlated with the traditional risk factors smoking $(\rho=0.05, P=0.05)$, SBP $(\rho=0.30, P<0.01)$, and HDL cholesterol $(\rho=-0.12$, $P<0.01$ ). No evidence for an interaction between fasting insulin and $M / I$ on carotid IMT was found. 
Table 2 General, lifestyle, and clinical characteristics according to sex and quartiles of $M / I$ values.

\begin{tabular}{|c|c|c|c|c|c|}
\hline & \multicolumn{2}{|c|}{ Men } & \multicolumn{2}{|c|}{ Women } & \multirow[b]{2}{*}{ All } \\
\hline & QI-III & QIV & QI-III & QIV & \\
\hline \multicolumn{6}{|l|}{ General characteristics } \\
\hline$n$ & 392 & 130 & 492 & 163 & 1177 \\
\hline Age (years) & $43.0(8.6)$ & $43.7(8.0)$ & $44.0(8.2)$ & $45.6(8.0)$ & $43.8(8.3)$ \\
\hline Family history of diabetes (\%) & 23 & 32 & 27 & $42^{*}-1$ & 27 \\
\hline \multicolumn{6}{|l|}{ Lifestyle characteristics } \\
\hline Frequency of smoking (\%) & 27 & 31 & 25 & 18 & 26 \\
\hline Alcohol intake (grams/week) ${ }^{a}$ & $73(110)$ & $81(142)$ & $35(65)$ & $26(40)^{\star}$ & $50(90)$ \\
\hline \multicolumn{6}{|l|}{ Clinical characteristics } \\
\hline BMI $\left(\mathrm{kg} / \mathrm{m}^{2}\right)^{\mathrm{a}}$ & $25.5(3.7)$ & $28.3(3.9)^{*}$ & $23.5(4.2)$ & $26.8(7.2)^{*}$ & $24.9(5.0)$ \\
\hline Waist circumference $(\mathrm{cm})$ & $91.1(9.3)$ & $99.4(9.7)^{*}$ & $78.8(10.4)$ & $87.0(12.9)^{*}$ & $86.3(12.5)$ \\
\hline Fat mass $(\mathrm{kg})$ & $17.0(6.8)$ & $24.0(8.1)^{\star}$ & $20.7(7.7)$ & $27.7(10.8)^{*}$ & $20.8(8.7)$ \\
\hline Total cholesterol $(\mathrm{mmol} / \mathrm{l})$ & $4.8(0.9)$ & $5.1(0.8)^{\star}$ & $4.7(0.9)$ & $4.9(0.9)^{*}$ & $4.8(0.9)$ \\
\hline HDL cholesterol (mmol/l) & $1.3(0.3)$ & $1.1(0.3)^{*}$ & $1.6(0.4)$ & $1.4(0.3)^{*}$ & $1.4(0.4)$ \\
\hline Triglycerides $(\mathrm{mmol} / \mathrm{l})^{\mathrm{a}}$ & $1.0(0.6)$ & $1.4(1.0)^{\star}$ & $0.8(0.4)$ & $1.0(0.7)^{*}$ & $0.9(0.6)$ \\
\hline Systolic blood pressure $(\mathrm{mmHg})$ & $122(11)$ & $124(10)$ & $112(12)$ & $117(13)^{*}$ & $117(12)$ \\
\hline Diastolic blood pressure (mmHg) & $76(8)$ & $78(6)^{*}$ & $72(8)$ & $75(8)^{*}$ & $74(8)$ \\
\hline Fasting glucose OGTT ${ }^{\mathrm{b}}(\mathrm{mmol} /)^{\mathrm{a}}$ & $5.2(0.6)$ & $5.3(0.6)$ & $4.9(0.6)$ & $5.0(0.7)$ & $5.1(0.7)$ \\
\hline $2 \mathrm{~h}$ glucose $\mathrm{OGTT}^{\mathrm{b}}(\mathrm{mmol} / \mathrm{l})^{\mathrm{a}}$ & $5.3(1.7)$ & $6.3(2.0)^{*}$ & $5.4(1.7)$ & $6.4(2.8)^{*}$ & $5.6(1.9)$ \\
\hline Fasting insulin $\mathrm{OGTT}^{\mathrm{b}}(\mathrm{pmol} / \mathrm{l})^{\mathrm{a}}$ & $28(19)$ & $51(29)^{\star}$ & $25(17)$ & $44(29)^{*}$ & $31(23)$ \\
\hline $2 \mathrm{~h}$ insulin $(\mathrm{pmol} / \mathrm{l})^{\mathrm{a}}$ & $112(117)$ & $269(280)^{*}$ & $138(116)$ & $271(244)^{\star}$ & $147(152)$ \\
\hline Average OGTT ${ }^{\mathrm{b}}$ insulin response $(\mathrm{pmol} / /)^{\mathrm{a}}$ & $187(108)$ & $358(236)^{*}$ & $180(108)$ & $313(211)^{*}$ & $203(154)$ \\
\hline$M / I\left(\mu \mathrm{mol} / \mathrm{min} \text { per } \mathrm{kg}_{\mathrm{ffm}} \text { per } \mathrm{nM}\right)^{\mathrm{a}}$ & $128(69)$ & $64(22)^{\star}$ & $168(71)$ & $85(28)^{\star}$ & $130(89)$ \\
\hline IMT in $\mathrm{CCA}^{\mathrm{c}}(\mathrm{mm})^{\mathrm{a}}$ & $0.60(0.11)$ & $0.64(0.10)^{\star}$ & $0.58(0.11)$ & $0.60(0.11)$ & $0.59(0.11)$ \\
\hline
\end{tabular}

Data are means (S.D.) *Statistically significant difference $(P<0.05$, adjusted for age and study center) compared with the $75 \%$ highest $M / I$ values. ${ }^{\mathrm{a}}$ Medians (interquartile range) and frequencies; QI-III denotes the $75 \%$ highest M/I values; QIV denotes the $25 \%$ lowest $M / /$ values.

${ }^{\mathrm{b}}$ Oral glucose tolerance test.

'Intima media thickness in common carotid artery.

Additional adjustment for smoking, SBP, and HDL cholesterol did not largely change the association between fasting insulin and IMT in men $(B=0.015$ (0.003-0.027)), but the association between fasting insulin and IMT in women became statistically nonsignificant $(0.005(-0.005$ to 0.015$))$. There was no evidence for multi-collinearity in the regression model.

\section{Discussion}

We have measured fasting insulin and insulin sensitivity by the hyperinsulinemic euglycemic clamp at the same time in a large healthy population. Results showed that fasting insulin is more strongly associated with cardiometabolic risk and preclinical atherosclerosis than clamp-derived insulin sensitivity.

We found that men more often had the metabolic syndrome than women. This result coincides with the findings of several other studies that assessed the prevalence of the metabolic syndrome in European populations (15-17). Although mean fasting insulin concentrations were higher in men and mean $M / I$ was higher in women, fasting insulin seemed to be a stronger contributor to the cardiometabolic risk profile than insulin sensitivity in both men and women.

Our group has recently shown that the average insulin response during OGTT contributed to the cardiovascular risk profile, independently from clampderived insulin sensitivity and waist girth (8). In the

Table 3 Spearman's $\rho$ correlations between fasting insulin, $M / I$, and cardiometabolic risk factors incorporated in the metabolic syndrome according to gender.

\begin{tabular}{|c|c|c|c|c|c|c|}
\hline & \multicolumn{2}{|c|}{ Men } & \multicolumn{2}{|c|}{ Women } & \multicolumn{2}{|l|}{ All } \\
\hline & Fasting insulin & $M / I$ & Fasting insulin & $M / I$ & Fasting insulin & $M / I$ \\
\hline Fasting glucose & $0.29^{*}$ & -0.05 & $0.38^{*}$ & -0.03 & $0.36^{*}$ & $-0.11^{*}$ \\
\hline Waist circumference & $0.53^{*}$ & $-0.44^{\star}$ & $0.49^{*}$ & $-0.30^{*}$ & $0.49^{*}$ & $-0.44^{\star}$ \\
\hline Triglycerides & $0.41^{*}$ & $-0.33^{*}$ & $0.31^{*}$ & $-0.23^{\star}$ & $0.37^{\star}$ & $-0.33^{*}$ \\
\hline HDL cholesterol & $-0.35^{\star}$ & $0.31^{*}$ & $-0.37^{*}$ & $0.32^{*}$ & $-0.37^{*}$ & $0.39^{*}$ \\
\hline Systolic blood pressure & $0.11^{*}$ & -0.06 & $0.20^{*}$ & $-0.13^{*}$ & $0.19^{*}$ & $-0.18^{*}$ \\
\hline Diastolic blood pressure & $0.21^{*}$ & $-0.17^{\star}$ & $0.21^{*}$ & $-0.14^{*}$ & $0.23^{*}$ & $-0.20^{*}$ \\
\hline
\end{tabular}

*Statistically significant correlation $(P<0.05)$. 
Table $42 \times 2$ tables of the prevalence of the metabolic syndrome according to sex and quartiles of fasting insulin and $\mathrm{M} / \mathrm{I}$.

\begin{tabular}{|c|c|c|c|}
\hline & MII QI-III & MII QII & \\
\hline \multicolumn{4}{|c|}{ Metabolic syndrome in men (\%) } \\
\hline Fasting insulin QI-III & 4.7 & 11.3 & 5.6 \\
\hline \multirow[t]{2}{*}{ Fasting insulin QIV } & 21.6 & 39.0 & 32.0 \\
\hline & 6.9 & 27.7 & 12.1 \\
\hline \multicolumn{4}{|c|}{ Metabolic syndrome in women (\%) } \\
\hline Fasting insulin QI-III & 2.9 & 6.7 & 3.4 \\
\hline \multirow[t]{2}{*}{ Fasting insulin QIV } & 15.3 & 30.7 & 23.8 \\
\hline & 4.7 & 19.6 & 8.4 \\
\hline
\end{tabular}

In the case of fasting insulin, QI-III denotes the $75 \%$ lowest fasting insulin values and QIV denotes the $25 \%$ highest fasting insulin values; in the case of M/I, QI-III denotes the 75\% highest M/I values; QIV denotes the $25 \%$ lowest $\mathrm{M} / \mathrm{I}$ values. Italics indicate totals.

present study, the correlation between fasting insulin and insulin OGTT response was high, but both seem to reflect different entities. The correlation between $M / I$ and average OGTT insulin response was higher than that between $M / I$ and fasting insulin, suggesting that insulin response is more strongly associated with insulin sensitivity than fasting insulin.

While fasting insulin has been used as a surrogate measure for insulin sensitivity in numerous studies, the present study not only suggests that fasting insulin plays an important, independent role in cardiometabolic risk, but also that its role may even be larger than that of insulin sensitivity, at least in an overall healthy population. We found that unlike insulin sensitivity, fasting insulin was significantly related to all elements of the metabolic syndrome and that fasting insulin had stronger associations with the metabolic syndrome and with carotid IMT, a measure of systemic atherosclerosis, than insulin sensitivity. Our results are in line with the results of the previously mentioned prospective study in
Pima Indians and prospective studies in middle-aged white men, which showed that fasting insulin was an independent predictor of type 2 diabetes $(5,18,19)$. We also showed that fasting insulin was independently associated with carotid IMT, as was found in the IRAS study (7). The main strength of our study is that the results, in contrast to the above-mentioned studies, are from a cohort of healthy men and women between the ages of 30 and 60 in which we measured not only fasting insulin but also insulin sensitivity by the gold standard method, the hyperinsulinemic euglycemic clamp.

Fasting plasma insulin is the primary regulator of hepatic glucose output, which is the primary determinant of fasting glucose production. Results of a multinational study using the hyperglycemic clamp suggested that impaired fasting glucose reflects liver insulin resistance, while people with impaired glucose tolerance mainly have peripheral insulin resistance (20). In mice, knockout of the insulin receptor in the liver led to fasting and fed hyperglycemia, hyperinsulinemia, and consequently insulin resistance in peripheral tissues (21). These data suggest that fasting hyperinsulinemia and insulin resistance have a different underlying pathology and different consequences.

Long-term pathological consequences of fasting hyperinsulinemia could be diverse. The study in Pima Indians suggested that the independent effect of fasting hyperinsulinemia on the development of type 2 diabetes is mediated by the detrimental effects on early phase insulin secretion (5). The authors proposed that this is possibly caused by downregulation of insulin receptors in the pancreatic B cells. Chronic hyperinsulinemia can have several consequences. It has been suggested to lead to autonomic dysfunction, which subsequently leads to

Table 5 Prevalence of the presence of characteristics of the metabolic syndrome and the metabolic syndrome itself according to sex and quartiles of fasting insulin and $M / I$.

\begin{tabular}{|c|c|c|c|c|c|c|c|}
\hline & \multicolumn{2}{|c|}{$\%$ Men } & \multirow{2}{*}{$\begin{array}{c}\text { OR } \\
(95 \% \mathrm{Cl})\end{array}$} & \multicolumn{2}{|c|}{$\%$ Women } & \multirow{2}{*}{$\begin{array}{c}\text { OR } \\
(95 \% \mathrm{Cl})\end{array}$} & \multirow[b]{2}{*}{ All } \\
\hline & QI-III & QIV & & QI-III & QIV & & \\
\hline \multicolumn{8}{|l|}{ Fasting insulin } \\
\hline$n$ & 394 & 128 & & 495 & 160 & & 1177 \\
\hline Fasting glucose $\geq 5.6 \mathrm{mmol} / \mathrm{l}$ & 21.1 & 35.2 & $2.8(1.7-4.7)$ & 7.9 & 26.9 & $5.2(3.0-9.1)$ & 17.8 \\
\hline Waist $>102 \mathrm{~cm}$ men, $>88 \mathrm{~cm}$ women & 9.1 & 42.2 & $4.4(2.5-7.7)$ & 14.7 & 50.0 & $3.9(2.5-6.0)$ & 20.6 \\
\hline Triglycerides $\geq 1.7 \mathrm{mmol} / \mathrm{l}$ & 11.7 & 39.8 & $3.5(2.0-5.9)$ & 3.0 & 17.5 & $4.1(2.0-8.6)$ & 11.8 \\
\hline $\mathrm{HDL}<1.03 \mathrm{mmol} / \mathrm{l} \mathrm{men},<1.29 \mathrm{mmol} / \mathrm{l}$ women & 17.8 & 38.3 & $1.9(1.2-3.2)$ & 12.7 & 37.5 & $3.3(2.1-5.1)$ & 20.6 \\
\hline Blood pressure $\geq 130 / 85 \mathrm{mmHg}$ & 28.9 & 40.6 & $1.5(1.0-2.4)$ & 13.3 & 21.3 & $1.3(0.8-2.1)$ & 22.6 \\
\hline Metabolic syndrome & 5.6 & 32.0 & $5.4(2.8-10.3)$ & 3.4 & 23.8 & $5.1(2.6-9.9)$ & 10.0 \\
\hline \multicolumn{8}{|l|}{ M/I } \\
\hline$n$ & 392 & 130 & & 492 & 163 & & 1177 \\
\hline Fasting glucose $\geq 5.6 \mathrm{mmol} / \mathrm{l}$ & 23.2 & 28.5 & $0.7(0.4-1.3)$ & 11.4 & 16.0 & $0.5(0.3-1.0)$ & 17.8 \\
\hline Waist $>102 \mathrm{~cm}$ men, $>88 \mathrm{~cm}$ women & 11.7 & 33.8 & $1.7(0.9-3.0)$ & 16.1 & 45.4 & $1.8(1.1-2.8)$ & 20.6 \\
\hline Triglycerides $\geq 1.7 \mathrm{mmol} / \mathrm{l}$ & 12.8 & 35.4 & $1.9(1.1-3.4)$ & 4.1 & 14.1 & $1.7(0.8-3.6)$ & 11.8 \\
\hline $\mathrm{HDL}<1.03 \mathrm{mmol} / \mathrm{l} \mathrm{men},<1.29 \mathrm{mmol} / \mathrm{l}$ women & 17.9 & 37.7 & $1.6(1.0-2.9)$ & 14.2 & 32.5 & $1.7(1.0-2.7)$ & 20.6 \\
\hline Blood pressure $\geq 130 / 85 \mathrm{mmHg}$ & 29.6 & 38.5 & $1.0(0.6-1.7)$ & 12.2 & 24.5 & $1.7(1.0-2.9)$ & 22.6 \\
\hline Metabolic syndrome & 6.9 & 27.7 & $2.4(1.3-4.7)$ & 4.7 & 19.6 & $1.6(0.8-3.1)$ & 10.0 \\
\hline
\end{tabular}

Odds ratios are for quartile QIV versus quartiles QI-III, adjusted for age, study center, $M / l$ in the case of fasting insulin and fasting insulin in the case of $M / l$; in the case of fasting insulin, QI-III denotes the $75 \%$ lowest fasting insulin values and QIV denotes the $25 \%$ highest fasting insulin values; in the case of M/I, QI-III denotes the $75 \%$ highest $M / /$ values; QIV denotes the $25 \%$ lowest $M / /$ values. 
the development of type 2 diabetes and cardiovascular disease (22). A rat model in which chronic hyperinsulinemia was induced showed that the chronic high levels of insulin caused tachycardia and arterial baroreflex abnormalities independent of insulin resistance (23). Chronic hyperinsulinemia has also been proposed to promote coagulation and inflammation, which have recently been implicated in the development of the cardiometabolic syndrome $(24,25)$. A selective state of $24 \mathrm{~h}$ of hyperinsulinemia created in healthy volunteers produced elevated levels of several prothrombotic factors, monocyte tissue factor expression, and platelet CD40 ligand, indicative of a prothrombotic, proinflammatory, and proatherogenic state.

Having measured insulin sensitivity by the hyperinsulinemic euglycemic clamp in a general population is no doubt the biggest asset of this study. A limitation is that our study is of cross-sectional nature. Although we showed that fasting insulin concentrations and insulin resistance, as measured by clamp-derived insulin sensitivity, are independently associated with the metabolic syndrome and carotid IMT, we can draw no conclusions on their relative causal roles in the pathophysiology of the syndrome and atherosclerosis. However, the fact that some participants with high fasting insulin levels have metabolic risk factors without being insulin resistant suggests independent pathogenic effects of both fasting insulin and insulin resistance. Another limitation is that although the hyperinsulinemic euglycemic clamp has a better reproducibility than all other methods used to measure insulin sensitivity, the intraindividual variability of the $M / I$ ratio is estimated to range from 6 to $15 \%$ for the method we used (26-28). Also, variability within a person for the measurement of fasting insulin can be $22 \%$ (29). Intra-individual variation tends to attenuate associations, so in our study associations between fasting insulin and cardiometabolic risk will suffer more from underestimation than associations between $M / I$ and cardiometabolic risk. Although within person variability constitutes a limitation, we do not think it affects the direction of our conclusion.

Insulin resistance is believed to be one of the most important underlying factors of the cardiometabolic risk profile. Because measuring insulin sensitivity by the gold standard technique, the hyperinsulinemic euglycemic clamp, is very time consuming and expensive, fasting insulin is often used as a surrogate measure. We have now shown that doing so can lead to wrong conclusions; in a very large, healthy population, fasting hyperinsulinemia was an independent and even stronger contributor to cardiometabolic risk and atherosclerosis than insulin resistance as measured by hyperinsulinemic euglycemic clamp.

\section{Declaration of interest}

There is no conflict of interest that could be perceived as prejudicing the impartiality of the research reported.

\section{Funding}

The RISC study is partly supported by European Union grant (grant number QLG1-CT-2001-01252). Additional support for the RISC study has been provided by AstraZeneca (Sweden). The EGIR group is supported by Merck Santé (France). The Dutch subcohort was supported by additional grants from The Netherlands Heart foundation (grant number 2002B123) and Heineken International BV.

\section{Acknowledgements}

Dr R Catalini (Ancona, Italy) is thanked for his advice and help in preparing the carotid ultrasound protocol. (RISC recruiting centers: Amsterdam, The Netherlands: J Dekker, S de Rooij, G Nijpels, W Boorsma; Athens, Greece: A Mitrakou, S Tournis, K Kyriakopoulou, P Thomakos; Belgrade, Serbia: N Lalic, K Lalic, A Jotic, L Lukic, M Civcic; Dublin, Ireland: J Nolan, T P Yeow, M Murphy, C DeLong, G Neary, M P Colgan, M Hatunic; Frankfurt, Germany: T Konrad, H Böhles, S Fuellert, F Baer, H Zuchhold; Geneva, Switzerland: A Golay, E Harsch Bobbioni, V Barthassat, V Makoundou, T N O Lehmann, T Merminod; Glasgow, Scotland: J R Petrie (now Dundee), C Perry, F Neary, C MacDougall, K Shields, L Malcolm; Kuopio, Finland: M Laakso, U Salmenniemi, A Aura, R Raisanen, U Ruotsalainen, T Sistonen, M Laitinen, H Saloranta; London, England: S W Coppack, N McIntosh, J Ross, L Pettersson, P Khadobaksh; Lyon, France: M Laville, F Bonnet (now Rennes), A Brac de la Perriere, C Louche-Pelissier, C Maitrepierre, J Peyrat, S Beltran, A Serusclat; Madrid, Spain: R Gabriel, M E Sánchez, R Carraro, A Friera, S Perez; Malmö, Sweden (1): P Nilsson, M Persson, G Östling, (2): O Melander, P Burri; Milan, Italy: P M Piatti, L D Monti, E Setola, E Galluccio, F Minicucci, A Colleluori; Newcastle-upon-Tyne, England: M Walker, I M Ibrahim, M Jayapaul, D Carman, C Ryan, K Short, Y McGrady, D Richardson; Odense, Denmark: H Beck-Nielsen, P Staehr, K Hojlund, V Vestergaard, C Olsen, L Hansen; Perugia, Italy: G B Bolli, F Porcellati, C Fanelli, P Lucidi, F Calcinaro, A Saturni; Pisa, Italy: E Ferrannini, A Natali, E Muscelli, S Pinnola, M Kozakova; Rome, Italy: G Mingrone, C Guidone, A Favuzzi. P Di Rocco; Vienna, Austria: C Anderwald, M Bischof, M Promintzer, M Krebs, M Mandl, A Hofer, A Luger, W Waldhäusl, M Roden. Project Management Board: B Balkau (Villejuif, France), S W Coppack (London, England), J M Dekker (Amsterdam, The Netherlands), E Ferrannini (Pisa, Italy), A Mari (Padova, Italy), A Natali (Pisa, Italy), M Walker (Newcastle, England). Core laboratories and reading centers: Lipids Dublin, Ireland: P Gaffney, J Nolan, G Boran; Hormones Odense, Denmark: C Olsen, L Hansen, H Beck-Nielsen; Albumin:creatinine Amsterdam, The Netherlands: A Kok, J Dekker; Genetics Newcastle-upon-Tyne, England: S Patel, M Walker; Stable isotope laboratory Pisa, Italy: A Gastaldelli, D Ciociaro; Ultrasound reading centre Pisa, Italy: M Kozakova; ECG reading, Villejuif, France: M T Guillanneuf; Actigraph, Villejuif, France: B Balkau, L Mhamdi. Data Management Villejuif, France, Padova, and Pisa, Italy: B Balkau, A Mari, L Mhamdi, L Landucci, S Hills, L Mota. Mathematical modeling and website management Padova, Italy: A Mari, G Pacini, C Cavaggion; Coordinating office: Pisa, Italy: S A Hills, L Landucci. L Mota. Further information on the RISC study and participating centers can be found at www.egir.org.)

\section{References}

1 Laakso M. How good a marker is insulin level for insulin resistance? American Journal of Epidemiology 1993137 959-965.

2 Matthews DR, Hosker JP, Rudenski AS, Naylor BA, Treacher DF \& Turner RC. Homeostasis model assessment: insulin resistance and beta-cell function from fasting plasma glucose and insulin concentrations in man. Diabetologia 1985 28 412-419.

3 Katz A, Nambi S, Mather K, Baron AD, Follmann DA, Sullivan G \& Quon MJ. Quantitative insulin sensitivity check index: a simple, 
accurate method for assessing insulin sensitivity in humans. Journal of Clinical Endocrinology and Metabolism $2000 \mathbf{8 5}$ 2402-2410.

4 Legro RS, Finegood D \& Dunaif A. A fasting glucose to insulin ratio is a useful measure of insulin sensitivity in women with polycystic ovary syndrome. Journal of Clinical Endocrinology and Metabolism $1998832694-2698$.

5 Weyer C, Hanson RL, Tataranni PA, Bogardus C \& Pratley RE. A high fasting plasma insulin concentration predicts type 2 diabetes independent of insulin resistance: evidence for a pathogenic role of relative hyperinsulinemia. Diabetes $2000 \mathbf{4 9}$ 2094-2101.

6 Mykkanen L, Haffner SM, Ronnemaa T, Bergman RN \& Laakso M. Low insulin sensitivity is associated with clustering of cardiovascular disease risk factors. American Journal of Epidemiology 1997 146 315-321.

7 Howard G, O'Leary DH, Zaccaro D, Haffner S, Rewers M, Hamman R, Selby JV, Saad MF, Savage P \& Bergman R. Insulin sensitivity and atherosclerosis. The Insulin Resistance Atherosclerosis Study (IRAS) Investigators. Circulation 199693 1809-1817.

8 Ferrannini E, Balkau B, Coppack SW, Dekker JM, Mari A, Nolan J, Walker M, Natali A \& Beck-Nielsen H. Insulin resistance, insulin response, and obesity as indicators of metabolic risk. Journal of Clinical Endocrinology and Metabolism $2007922885-2892$.

9 Hills SA, Balkau B, Coppack SW, Dekker JM, Mari A, Natali A, Walker M \& Ferrannini E. The EGIR-RISC STUDY (The European group for the study of insulin resistance: relationship between insulin sensitivity and cardiovascular disease risk): I. Methodology and objectives. Diabetologia $200447566-570$.

10 Ferrannini E \& Mari A. How to measure insulin sensitivity. Journal of Hypertension $1998 \mathbf{1 6}$ 895-906.

11 O'Leary DH, Polak JF, Kronmal RA, Savage PJ, Borhani NO, Kittner SJ, Tracy R, Gardin JM, Price TR \& Furberg CD. Thickening of the carotid wall. A marker of atherosclerosis in the elderly? Cardiovascular Health Study Collaborative Research Group. Stroke $199627224-231$.

12 Mercuri M, McPherson D, Bassiouni H \& Glagov S. Non-invasive Imaging of Atherosclerosis Dordrecht: Kluwer, 1998.

13 Executive Summary of the Third Report of the National Cholesterol Education Program (NCEP). Expert Panel on Detection, Evaluation, and Treatment of High Blood Cholesterol in Adults (Adult Treatment Panel III). Journal of the American Medical Association $20012852486-2497$.

14 Grundy SM, Cleeman JI, Daniels SR, Donato KA, Eckel RH, Franklin BA, Gordon DJ, Krauss RM, Savage PJ, Smith SC Jr, Spertus JA \& Costa F. Diagnosis and management of the metabolic syndrome. An American Heart Association/National Heart, Lung, and Blood Institute Scientific Statement. Executive summary. Cardiology in Review 200513 322-327.

15 Balkau B, Charles MA, Drivsholm T, Borch-Johnsen K, Wareham N, Yudkin JS, Morris R, Zavaroni I, van Dam R, Feskins E, Gabriel R, Diet M, Nilsson P \& Hedblad B. European Group for the Study of Insulin Resistance (EGIR). Frequency of the WHO metabolic syndrome in European cohorts, and an alternative definition of an insulin resistance syndrome. Diabetes and Metabolism $2002 \mathbf{2 8} 364-376$.

$16 \mathrm{Hu}$ G, Qiao Q, Tuomilehto J, Balkau B, Borch-Johnsen K \& Pyorala K. Prevalence of the metabolic syndrome and its relation to all-cause and cardiovascular mortality in nondiabetic European men and women. Archives of Internal Medicine $2004 \mathbf{1 6 4}$ 1066-1076.

17 Villegas R, Perry IJ, Creagh D, Hinchion R \& O'Halloran D. Prevalence of the metabolic syndrome in middle-aged men and women. Diabetes Care 200326 3198-3199.

18 Charles MA, Fontbonne A, Thibult N, Warnet JM, Rosselin GE \& Eschwege E. Risk factors for NIDDM in white population. Paris prospective study. Diabetes 199140 796-7990.

19 Skarfors ET, Selinus KI \& Lithell HO. Risk factors for developing non-insulin dependent diabetes: a 10 year follow up of men in Uppsala. BMJ 1991303 755-760.

20 Meyer C, Pimenta W, Woerle HJ, Van Haeften T, Szoke E, Mitrakou A \& Gerich J. Different mechanisms for impaired fasting glucose and impaired postprandial glucose tolerance in humans. Diabetes Care 200629 1909-1914.

21 Michael MD, Kulkarni RN, Postic C, Previs SF, Shulman GI, Magnuson MA \& Kahn CR. Loss of insulin signalling in hepatocytes leads to severe insulin resistance and progressive hepatic dysfunction. Molecular Cell 20006 87-97.

22 Liao D, Cai J, Brancati FL, Folsom A, Barnes RW, Tyroler HA \& Heiss G. Association of vagal tone with serum insulin, glucose, and diabetes mellitus - the ARIC Study. Diabetes Research and Clinical Practice 199530 211-221.

23 Hong LZ \& Hsieh P. Hyperinsulinemia instead of insulin resistance induces baroreflex dysfunction in chronic insulin-infused rats. American Journal of Hypertension 200720 451-458.

24 Vaidyula VR, Rao AK, Mozzoli M, Homko C, Cheung P \& Boden G. Effects of hyperglycemia and hyperinsulinemia on circulating tissue factor procoagulant activity and platelet CD40 ligand. Diabetes $200655202-208$.

25 Vaidyula VR, Boden G \& Rao AK. Platelet and monocyte activation by hyperglycemia and hyperinsulinemia in healthy subjects. Platelets 200617 577-585.

26 Bokemark L, Froden A, Attvall S, Wikstrand J \& Fagerberg B. The euglycemic hyperinsulinemic clamp examination: variability and reproducibility. Scandinavian Journal of Clinical and Laboratory Investigation $2000 \mathbf{6 0} 27-36$.

27 Mather KJ, Hunt AE, Steinberg HO, Paradisi G, Hook G, Katz A, Quon MJ \& Baron AD. Repeatability characteristics of simple indices of insulin resistance: implications for research applications. Journal of Clinical Endocrinology and Metabolism 200186 5457-5464.

28 Soop M, Nygren J, Brismar K, Thorell A \& Ljungqvist O. The hyperinsulinaemic-euglycaemic glucose clamp: reproducibility and metabolic effects of prolonged insulin infusion in healthy subjects. Clinical Science 200098 367-374.

29 Mooy JM, Grootenhuis PA \& de Vries H. Intra-individual variation of glucose, specific insulin and proinsulin concentrations measured by two oral glucose tolerance tests in a general Caucasian population: the Hoorn Study. Diabetologia 199639 298-305.

Received 4 May 2009

Accepted 12 May 2009 